\title{
GEOGRAPHIC INFORMATION SYSTEM FOR FLOOD MANAGEMENT BY CASCADE MODEL PREDICTIVE CONTROL (MPC)
}

\author{
Kajwis KLAHAN ${ }^{10}$, Suwatana CHITTALADAKORN ${ }^{1}$, Sitang PILAILAR ${ }^{1}$
}

DOI : 10.21163/GT_2021.162.10

\begin{abstract}
:
The number of river floods has increased worldwide, as well as in Nakorn Ratchasima Province in Thailand. To prevent disasters, the Royal Irrigation Department (RID) constructed thirteen regulating structures to control discharges. Currently, the local controllers spatially control these structures to minimize the subsystem's damage, regardless of the effects on the overall system performance. In this study, the concept of combining real-time flood management tools and the cascade Model Predictive Control (MPC) as well as application of GIS has been proposed and verified with the 2013 flood event. The distributed control of the existing hydraulic structures on the large scale of the Lamtakong River made optimal use of the retention basin storage capacity with the considerations of both local performance and global system interactions. The model proposes an optimal gate opening of each cascade at the specified time, from the beginning until the end of flood hydrographs. The results of the controlled water level indicate the efficiency of the CMPC, which is more satisfied satisfactory than the PID and practice technique of RID, as evidenced by the water level of $0.5 \mathrm{~m}$ that is lower than the level of the riverbank at Nakhon Ratchasima City. A comparison of flood areas between the historical flood in year 2013 and Management by CASCADE MPC shows by GIS flood map that in the case of Management by CASCADE MPC, it can reduce the flood area in Nakhorn Ratchasima city by almost $60 \%$.
\end{abstract}

Key-words: Model Predictive Control; Cascade MPC; Flood management; Flood Map; GIS

\section{INTRODUCTION}

River floods are a natural hazard that causes loss of life, devastating damage to properties, and adverse economic and environmental impacts (Vermuyten 2018). They typically occur when rivers exceed their embankments due to long periods of rainfall. As a result, the number of river floods has increased worldwide during the last decade, as well as in Thailand. Fig.1 shows the historical flood of 2010 (RID 2020) in Nakorn Ratchasima Province in the northeastern part of Thailand that caused suffering to more than one million people (Fig. 1), and four deaths. The damages covered the municipality area, the paddy fields, and farms. It seems that the flood warning system and situation management did not efficiently operate. Although the actual situation at the advent of upstream events was reported to the central operation center, the flood forecast, and scenario analysis seem not to have been appropriately performed due to the complication of the river network and existing management scheme. The problem caused difficulty for the local water administration of the Royal Irrigation Department (RID), who spatially controls the thirteen regulating structures along the Lamtakong River.

\footnotetext{
${ }^{1}$ Department of Water Resources Engineering, Kasetsart University, Bangkok, Thailand; kajwis.k@ku.th, fengswc@ku.ac.th,fengstpl@ku.ac.th
} 


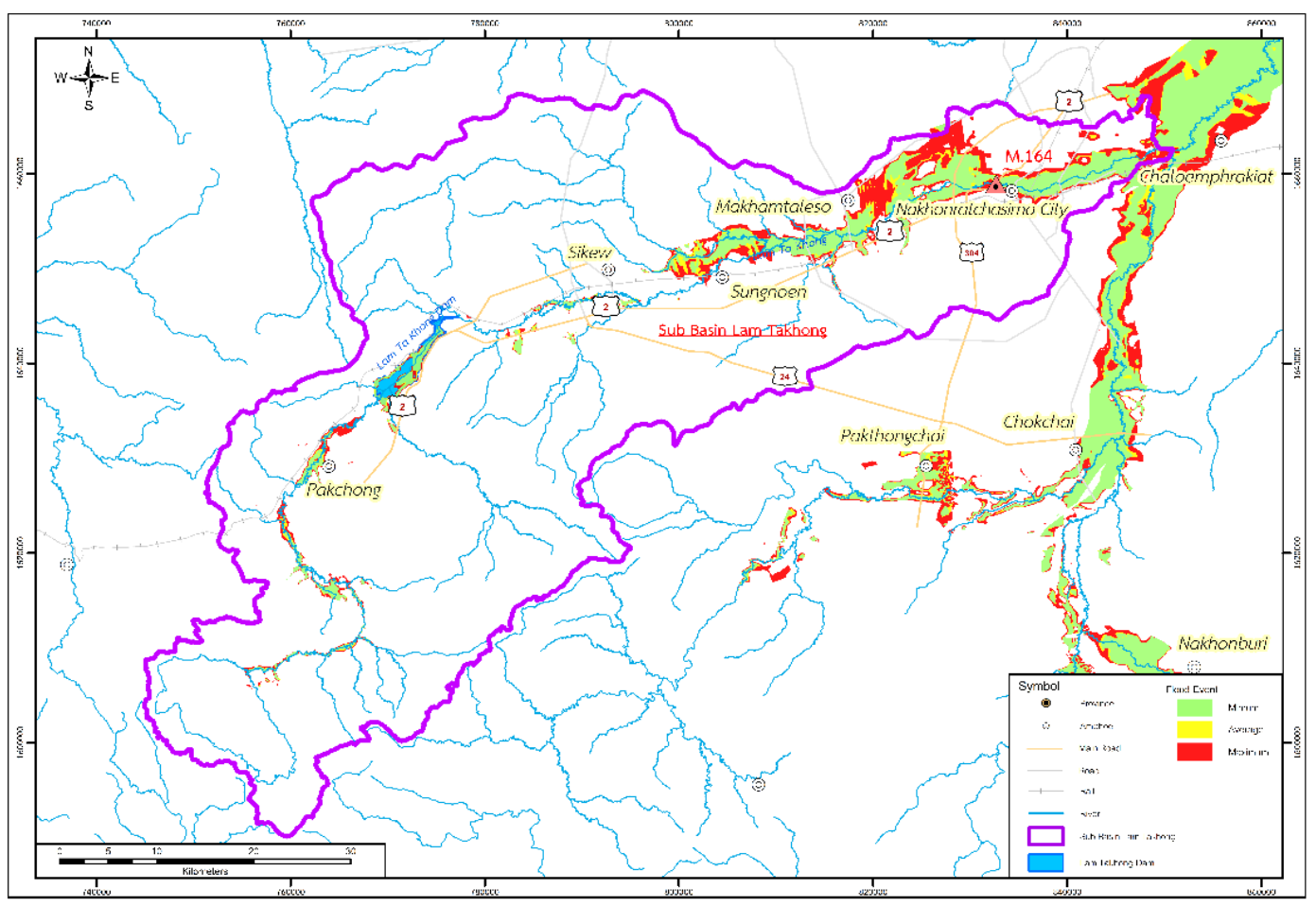

Fig. 1. Historical flood map of Lamtakong River, year 2013.

\section{STUDY AREA}

The Lamtakong River is an the most important tributary of the Mun River in northeastern Thailand, and its upstream section is between Khao Faa, Pak Chong District, Nakhon Ratchasima Province, and Khao Falami, Muang Nakhon Nayok District. It flows through communities in Pak Chong District, Sikhio District, Sung Noen District, and Nakhon Ratchasima City Municipality until it drains into the Mun River at Chakkarat District, with a total length of about $220 \mathrm{~km}$. Fig. 2 illustrates the flow schematic of the Lamtakong River, with several branches, and the Lamtakong Dam at Sikhio District upstream. The most important one is the Lamboriboon River, which has a total length of 35 $\mathrm{km}$. It flows almost parallel to the Lamtakong through Muang Nakhon Ratchasima District and converges with the original Lamtakong at Chaloem Phrakiat District before flowing into the Mun River.

In normal condition, the water is conserved mainly for irrigation purposes under the allocation of the RID staff, who are responsible for controlling the hydraulic structures with movable gates, as depicted in Fig. 2. Thus, the flow is controlled reach to reach. However, under the condition that the flow at the M.164 water metering station exceeds $65 \mathrm{cum} / \mathrm{s}$, the situation is then shifted to flood surveillance. Eleven gates are promptly raised to 50\%; the opening and closing of the gates are then manually controlled based on the local staff's expertise with the consideration of flow time lag from reach to reach. It means that objective functions and constraints are changed as conditions dictate.

According to the floods and damages to the communities and economic areas in Nakorn Ratchasima in the past, centralized control seems impossible due to the large-scale river systems. Likewise, the local water administration of RID appears incapable of spatially handling the hydraulic structures well. Therefore, this study proposes the concept of combining flood management with the cascade Model Predictive Control, taking the most advantage of the existing complex thirteen regulating structures to control the flow, and present the results of the analysis for flood areas that can be alleviated by a GIS system. 


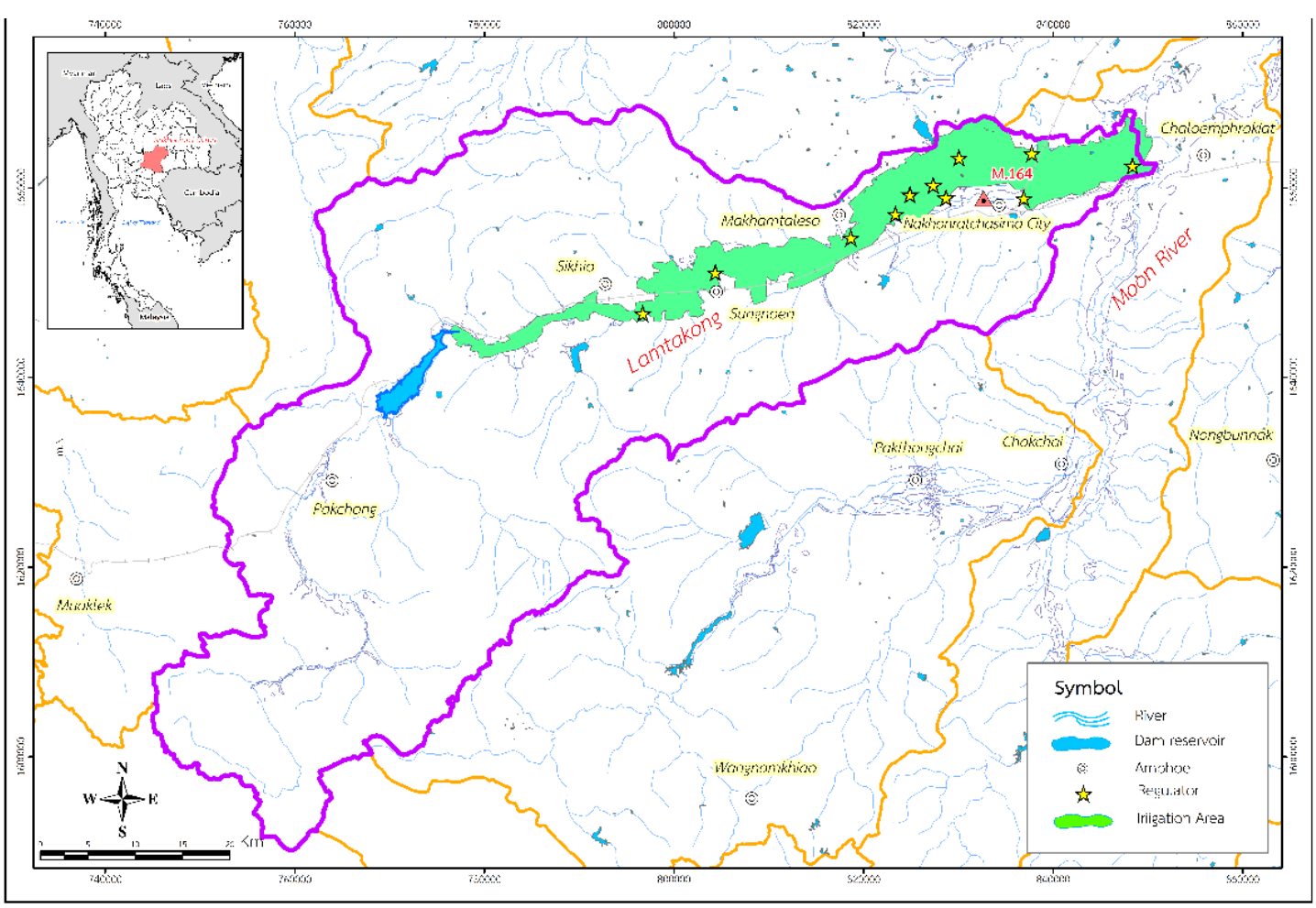

Fig. 2. Study area and river network.

\section{DATA AND METHODS}

\subsection{Flood Management Model}

Real-time water control models for flood forecasting and reservoir operations have been developed for several decades. The United States Army Corps of Engineers has developed water control systems that consist of data acquisition and processing, precipitation analysis, flow forecasting, reservoir system analysis, including data and simulation result graphical display since 1982 (Leon et al., 2014) . During the same period, another flood management type model was developed by the Savannah District of the United States Army Corps of Engineers (USACE Environmental Laboratory 1987). It consists of the rainfall-runoff model, hydrologic (lumped) routing computations for reservoirs, and hydraulic (distributed) unsteady flow routing based upon the numerical solution of Saint Vernant equations. Later, Unver et al., 1987 (USACE - Environmental Laboratory 1987) developed a real-time management model by combining techniques for onedimensional unsteady flow routing, rainfall-runoff modeling, graphical display, and interactive software capability. However, each model's accuracy depends on catchment characteristics and catchment response to rainfall, types of flood forecasting models, and various uncertainties, significantly influencing the decision-making process. Therefore, it is necessary to consider uncertainties in the real-time control process and real-time flood forecasts.

Model Predictive Control (MPC) has been found to eliminate model deviations and limit performance loss due to uncertainties. It is also known for its proactive control strategy, which is an advantage for future flood events. Breckpot et al. (2013) reported that MPC was successfully used for flood control and set-point control of the Demer river in Belgium, consisting of multiple reaches, gates, junctions, and reservoirs. Besides, the study of Falk et al. (2016) also indicated that MPC could solve the optimization problem of gates and dams in a large-scale river network in Australia. 


\subsection{Model Predictive Control}

Model Predictive Control (MPC) originates from the chemical process industry, but it has great value in various applications ranging from food processing to automotive and aerospace applications (Breckpot, 2013).

Since it formulates the control problem as an optimization problem, it has been used for river control during different operating conditions (Barjas Blanco et al., 2008; Evans et al., 2011; Wahlin and Zimbelman, 2018; López Rodríguez et al., 2017; Nguyen et al., 2017; Wang et al., 2017; and Tian et al., 2017). Furthermore, the predictive control strategies are widely accepted due to the intuitiveness and explicit constraint handling.

MPC is a control strategy that uses the system's model to make future predictions to minimize the objective function. Blanco (2008) mentioned that the three primary components of MPC are as follows:

- a process model is used to determine the future outputs within a time window with length $\mathrm{N}$, the prediction horizon. These future outputs are determined by future control actions and the current state of the system.

- an objective function is minimized. The objective function is typically a quadratic function that tries to minimize the water level errors and the gate movement by adjusting the unknown control inputs. Typically, the objective function is also subject to constraints.

- once the sequence of future control actions that minimize the desired objective function is determined, only the first set of control actions is implemented in the system. The system is then updated by measuring the target level.

In this study, the process model is nonlinear, as various process conditions and disturbances demand suitable process identification. All model predictive control algorithms minimize the following optimization algorithm by minimizing the cost function $\mathrm{J}$.

A generic MPC framework is described as:

$$
\begin{aligned}
& \text { Current state: } x_{o}=x \\
& \text { System model: } x_{k+1}=f\left(x_{k}, u_{k}\right) \\
& \text { Cost function: } J\left(x_{o}\right)=\min \sum_{k=0}^{N-1} l_{k}\left(x_{k}-u_{k}\right)
\end{aligned}
$$

where:

$N$ is the prediction horizon, $X_{K}$ (e.g., measured water level) and $U_{K}$ (e.g., target water level) are two constraints given for the states $X_{K}$ and the inputs $U_{K}$ at a time step $k$, respectively.

The reasonable values are predicted by the system model, thus reaching an expected control performance. For the MPC design, the cost function and constraints are the main two sections. Here, the current state, $\mathrm{X}_{\mathrm{O}}$, is used as the initial state for control predictions. The prediction process is continually repeated further to calculate the control signals in every time step. The basic idea of MPC (Song et al., 2020) is using a process model that predicts the system's behavior over a specified (finite) prediction horizon, as shown in Fig. 3. 


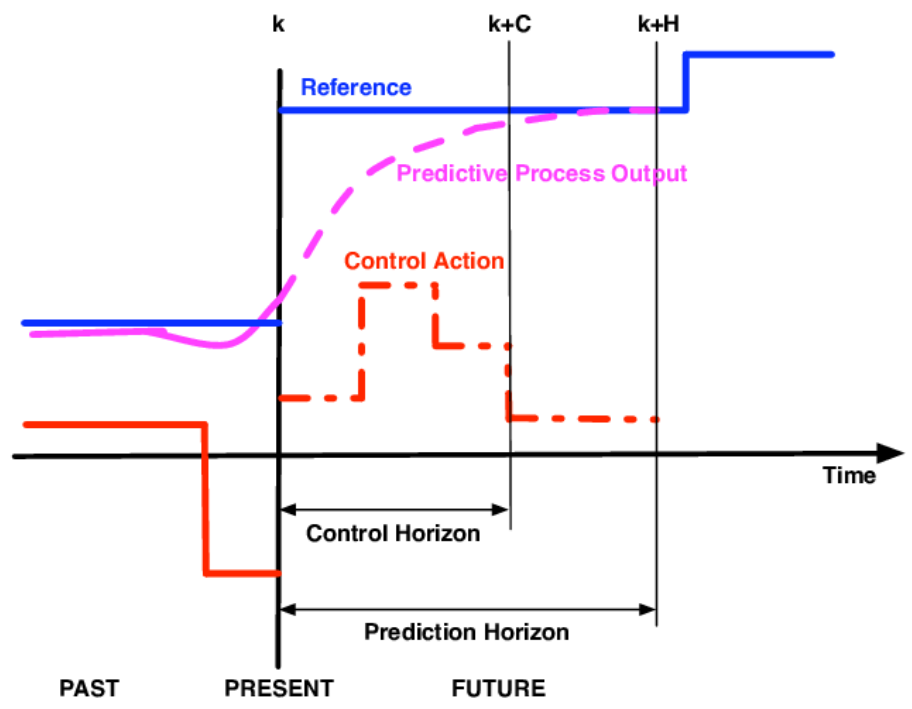

Fig. 3. Model Predictive Control Basis.

\subsection{Cascade Concept}

The original hydrodynamic analysis is considered holistic with related variables from upstream to downstream, i.e., inflow, cross-section, dimensions of key regulators with its water level upstream-downstream, gate operation information, and downstream boundary. It centrally considers all the regulators in the system by opening and closing gate various discharges. The analysis needs to consider many variables and intricate patterns; then there could be a considerable number of alternatives. Such a centralized controlling system from a big picture perspective would make spatial decisions errors. Besides, in the case of more than ten thousand possible alternatives (Fig. 4), it would give rise to extensive use of computational resources and cause delays in assessing a situation and making decisions to manage a flooding situation that arises. Thus, the decentralized approach will scale better for a large and complex system. Each controller's objective is to locally determine the actions appropriate to a situation and optimize the system's behavior.

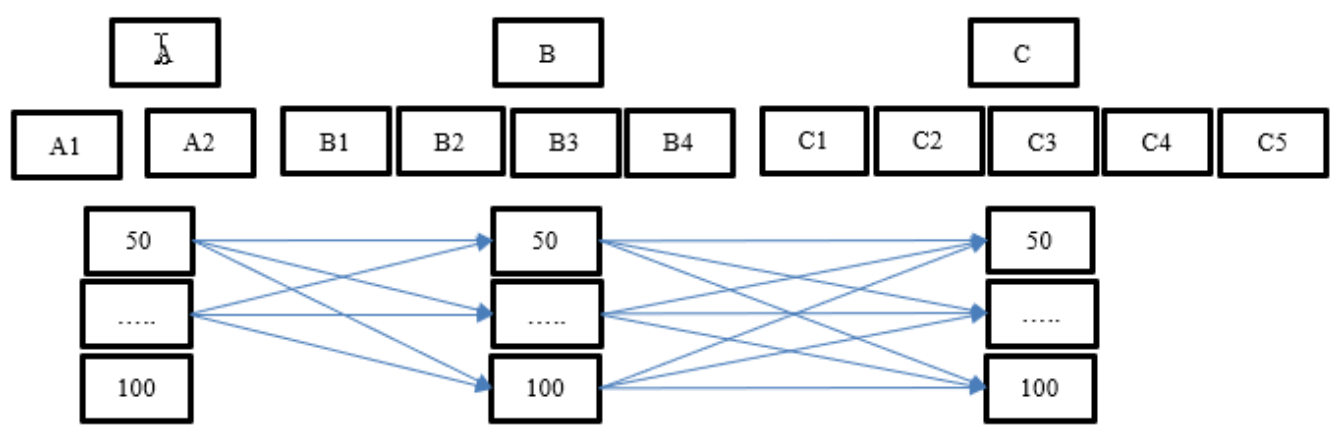

Fig. 4. Case of the Considered Integral System. 
Combining the optimized decentralized control in terms of the big picture of the system would lead to better results; thus, the cascade management concept is considered. The complex river system is divided into reaches according to the sets of regulators. The physical constraints of each reach are concerns; thus, the local target water level is set, as the cascade's concept is shown in Fig. 5. The proper gate opening and closing will be rapidly defined to optimize the flow with less downstream effect. Since the proper spatial alternatives are evaluated, the global effect will then be assessed from the downstream control strategy. Once the final system measures are set up, the system's new state is further updated.

\section{CASCADE CCi}

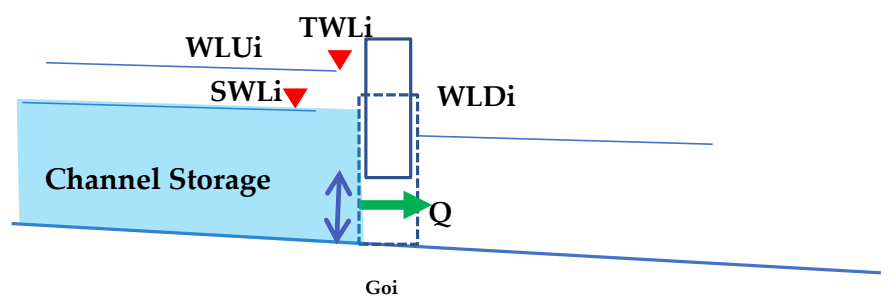

Fig. 5. Concept of Cascade's Control Water Level.

The concept of Cascade's Control Water Level is shown in Fig. 5, where TWLi is Target Water level upstream at cascade i, WLUi is Calculate Water level upstream at cascade i, SWLi is Storage Water upstream at cascade $\mathrm{i}$, and WLDi is Calculate Water level downstream at cascade $\mathrm{i}$.

\subsection{Methodology}

The methodology for making the decision is shown in Fig. 6. It is started by collecting data such as topography, cross section, land use, digital terrain model, hydrology, and regulator dimension. Next step is to set cascade network and to input the collected data to the geodatabase in the HECRAS. The water profile in the cascade will then be calculated by the HEC-RAS hydrodynamic model, and the CASCADE MPC is applied to find the optimum gate opening for each time step. The target water level will then be checked and measured. If it is close to a target value, it will transmit the parameters to perform a calculation in the subsequent cascade. The system will continue calculating until all cascades are completed and gotten the optimum result of gate operation setting. Finally, the result water level data will be exported in ARC-GIS to create a GIS flood map area for making a decision.

This study presents the concept of combining real-time flood management tools and the cascade MPC, so it is tested under a hypothetical condition that there are adequate onsite CCTVs to report real-time water levels and situations with sufficient computer resources. First, the flood situation is of primary concern, in which the condition of local flood management limits with its reach's embankment elevation is monitored. Then the global image is re-calculated under the condition of water level monitoring at the M.164 station. However, the lateral flow is excluded; just the channel flow from downstream of the Lamtakong Dam. Thus, the 2013 flood conditions, where the maximum flow was $90 \mathrm{cum} / \mathrm{s}$, which was lower than the maximum capacity of the Lamtakong River, are applied in this test. 


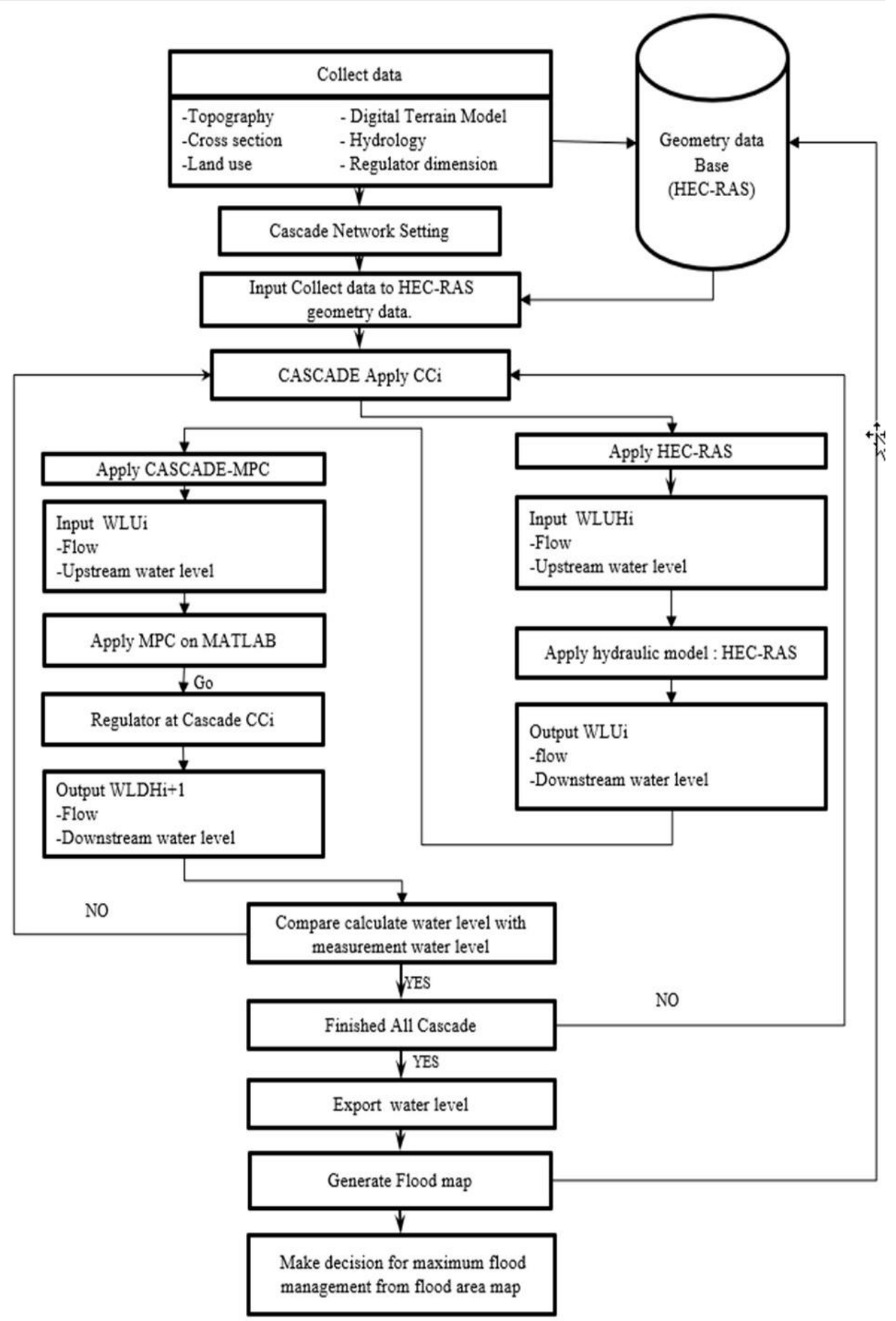

Fig. 6. Summarized procedure of study. 


\subsubsection{Cascade Network Setting}

According to the existing hydraulic structures, the $220 \mathrm{~km}$ of the concerned Lamtakong River is divided into seven cascades, CC1 to CC7, as shown in Fig. 7 The capacity of each reach is 0.65 , $0.24,0.19,0.24,0.28,0.24$, and $0.32 \mathrm{MCM}$, respectively. The study also includes the $35 \mathrm{~km}$ of the Lamboriboon River that flows parallel to the Lamtakong and converges with the original Lamtakong at Chaloem Phrakiat District. It is divided into seven cascades as well where each reach's capacity is $0.95,0.033,0.16,0.23,0.068,0.068$, and $0.12 \mathrm{MCM}$, respectively.

Once the flow from upstream enters $\mathrm{CC} 1$, all gate setting heights are precalculated, and then the water level of each reach is analyzed. The water level at M.164 is rechecked since it is the surveillance point to protect the Nakorn Ratchasima City Municipality. If there is a possibility of a flood, the excess water will be diverted towards the Lamboriboon River, with some water diverted through the diversion canal to Bungphudsar Reservoir in CC10. Again, the gate opening height of all regulators downstream of $\mathrm{CC} 3$ will be re-calculated. The global image of the basin will then be relooped. The optimized gate settings will finally be proposed to the local controllers within a few minutes of the completion of the computer simulation.

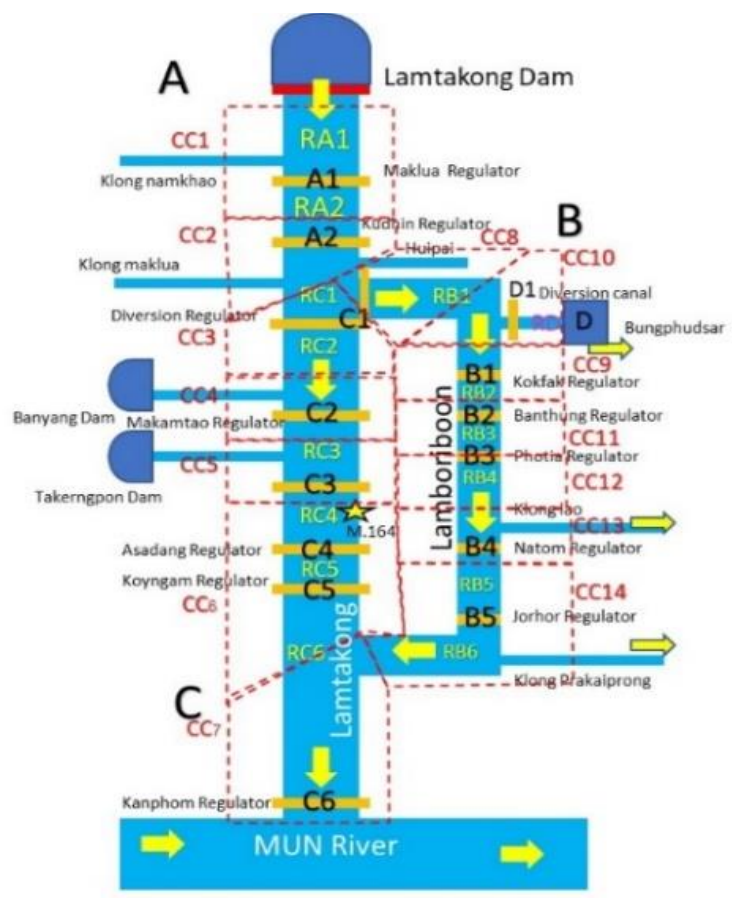

(a)

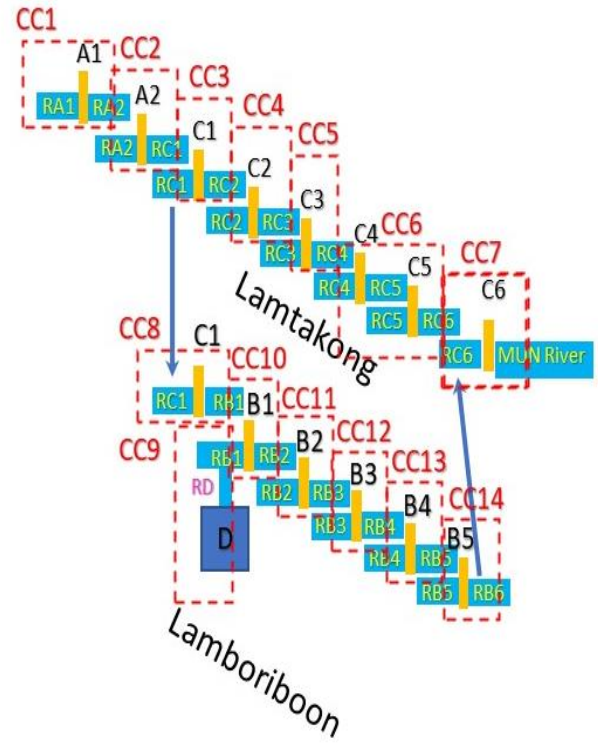

(b)

Fig. 7. Lamtakong and Lamboriboon Systems Cascade.

$\begin{array}{ll}\text { (a) Schematic of system cascade. } & \text { (b) Profile of system cascade. }\end{array}$

Fig. 8 illustrates the cascade concept where each reach's optimization is for adjusting the manipulated variable based on the MPC control to minimize the target's water level error. WLUi is the water height at the upstream section, WLDi is the water height at the downstream stretch, Q is the flow through each regulator, Goi is the Gate opening for regulator i, si is the slope of each cascade, $\mathrm{CC} i$ is Cascade number i where $\mathrm{i}$ is from 1 to 14 and $\mathrm{Li}$ is the length from reach $\mathrm{CCi}$. Since each reach of Lamtakong and Lamboriboon has different characteristics, it results in differences in target water level, as shown in Table 1. 


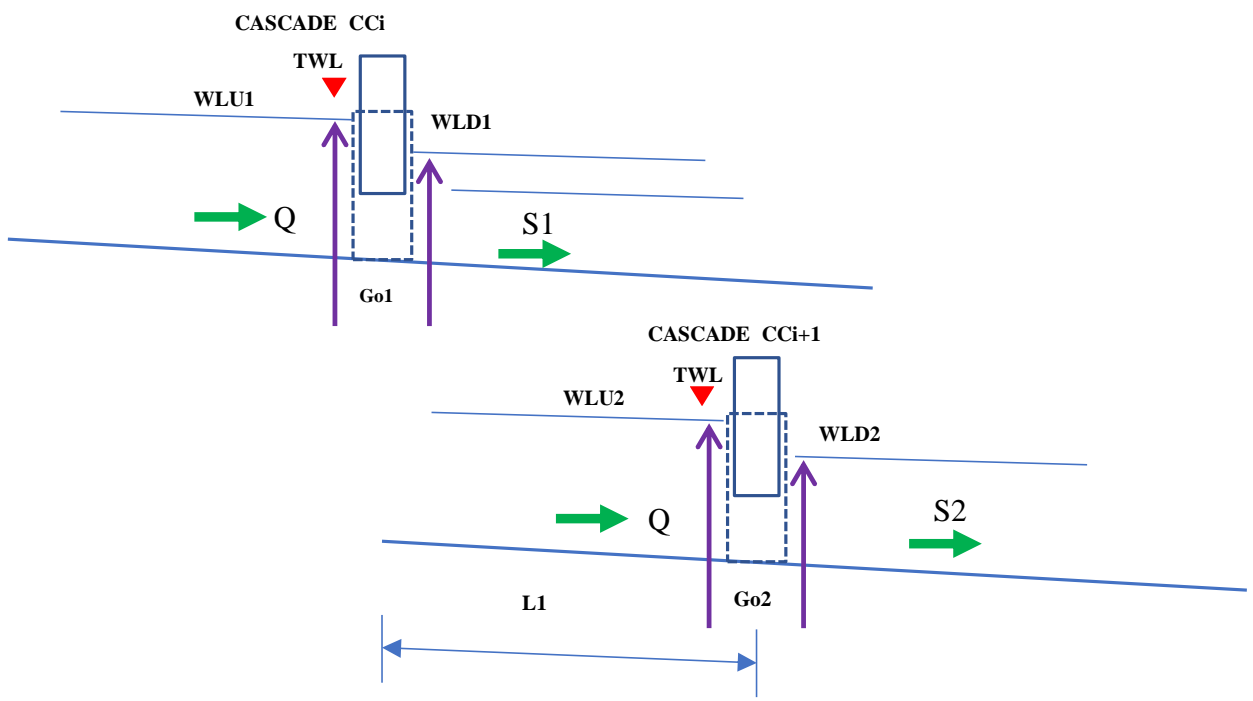

Fig. 8. Cascade Analysis Concepts.

Table 1.

Physical Characteristics of Cascades of Lamtakong and Lamboriboon.

\begin{tabular}{|c|c|c|c|c|c|c|c|}
\hline \multicolumn{8}{|c|}{ Lamtakong } \\
\hline Dimension & CC1 & $\mathrm{CC} 2$ & $\mathrm{CC} 3$ & $\mathrm{CC} 4$ & $\mathrm{CC} 5$ & CC6 & $\mathrm{CC7}$ \\
\hline Length of cascade $(\mathrm{L}, \mathrm{m})$. & 33,000 & 12,000 & 19,250 & 9,100 & 8,150 & 11,500 & 12,770 \\
\hline Target water level,TWL & 219 & 209 & 194 & 188 & 183 & 175 & 167 \\
\hline gate width & 4.5 & 4.5 & 6.0 & 4.5 & 4.5 & 3.5 & 2.5 \\
\hline gate height & 1.8 & 1.8 & 3.3 & 3.0 & 5.2 & 4.0 & 4.0 \\
\hline n of gate & 5 & 5 & 1 & 4 & 3 & 3 & 5 \\
\hline Gate coefficient & 0.6 & 0.6 & 0.6 & 0.6 & 0.6 & 0.6 & 0.6 \\
\hline Bed slope (S) & 0.00046 & 0.00030 & 0.00125 & 0.00031 & 0.00055 & 0.00098 & 0.00070 \\
\hline Manning $\mathrm{n}$. & 0.00032 & 0.00032 & 0.00032 & 0.00032 & 0.00032 & 0.00032 & 0.00032 \\
\hline \multicolumn{8}{|c|}{ Lamboriboon } \\
\hline Dimension & $\mathrm{CC} 8$ & CC9 & CC10 & CC11 & CC12 & CC13 & CC14 \\
\hline Length of cascade (L,m.) & 19,250 & 1,870 & 1,890 & 8,600 & 3,750 & 6,380 & 11,520 \\
\hline Target water level,TWL & 194 & 192 & 191 & 185 & 183 & 179 & 174 \\
\hline gate width & 6.0 & 4.2 & 3.0 & 4.0 & 4.0 & 4.0 & 4.0 \\
\hline gate height & 3.3 & 4.3 & 3.0 & 4.5 & 3.0 & 1.8 & 1.8 \\
\hline n of gate & 5 & 2 & 2 & 3 & 3 & 3 & 3 \\
\hline Gate coefficient & 0.6 & 0.6 & 0.6 & 0.6 & 0.6 & 0.6 & 0.6 \\
\hline Bed slope (S) & 0.0008 & 0.00010 & 0.00053 & 0.00317 & 0.00023 & 0.00107 & 0.00078 \\
\hline Manning $\mathrm{n}$. & 0.00032 & 0.00032 & 0.00032 & 0.00032 & 0.00032 & 0.00032 & 0.00032 \\
\hline
\end{tabular}

The collected geometry data of river system and topography data are imported into the geodatabase for use in HECRAS (see Fig. 9). 


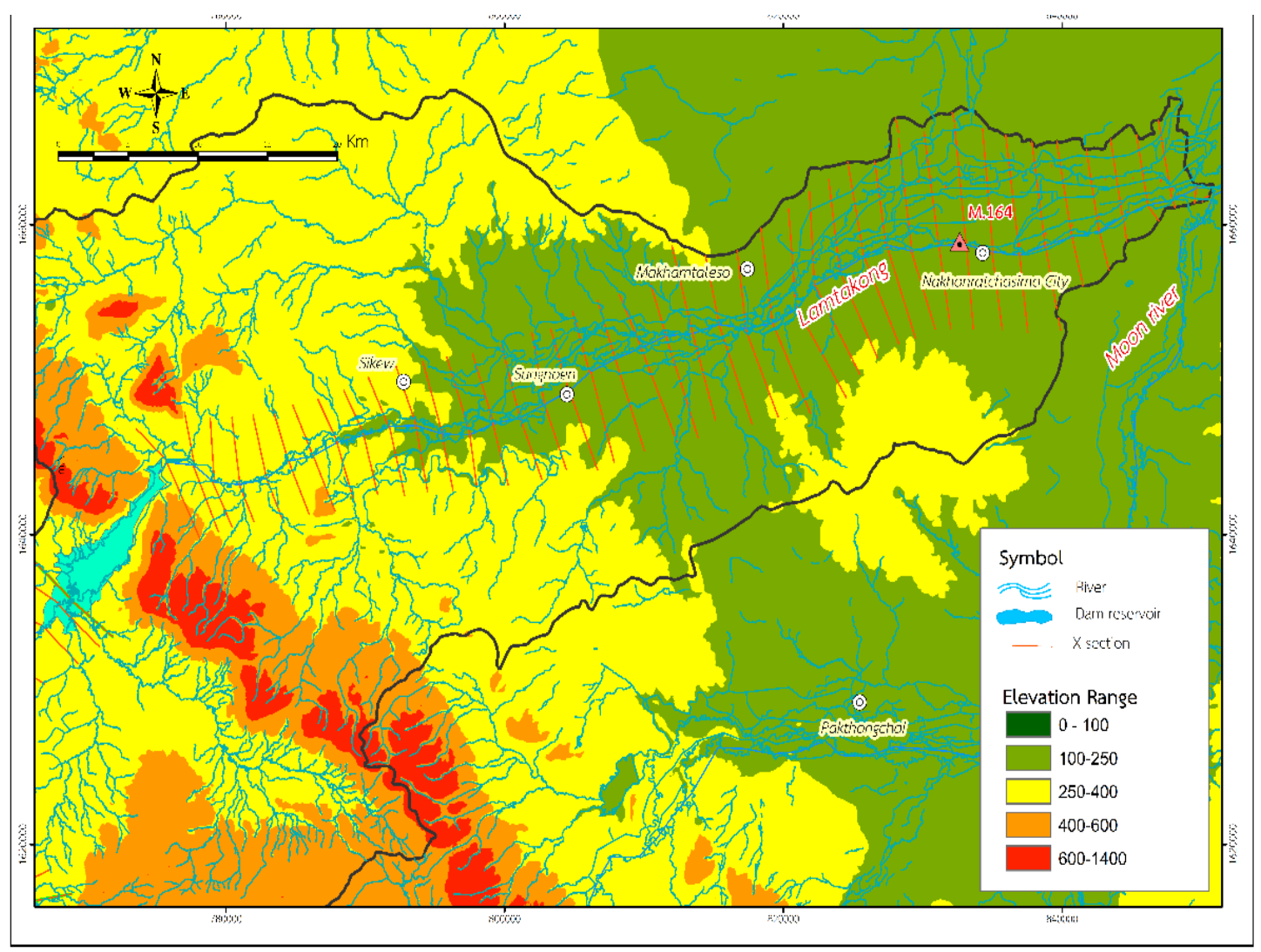

Fig. 9. Geometry data.

\subsubsection{Cascade MPC development}

\section{(1) HECRAS and MPC links}

This study attempts to manage flows both on local and global scales. For the single cascade calculation, the profile of the water level from the upstream cascade to the downstream cascade is calculated by HEC-RAS which is a widely used software application that can perform one and twodimensional hydraulic calculations for a full network of Lamtakong Basin.

The combination HEC-RAS and cascade model established in this study will involve applying MATLAB scripts to write input files, reading output files, making plots, executing parallel computations, and performing fully-automated functions of HEC-RAS through a HEC-RAS CONTROLLER (Modelling and Leon 2018). Water level Upstream (Hu) from HEC-RAS will be sent to MPC (Fig. 10).

The discharge of each cascade's sliding gate depends on the difference between the water heights of upstream $\mathrm{Hu}$ and downstream Hd around the hydraulic gates. Therefore, it can be calculated as equations (4) and (5): 


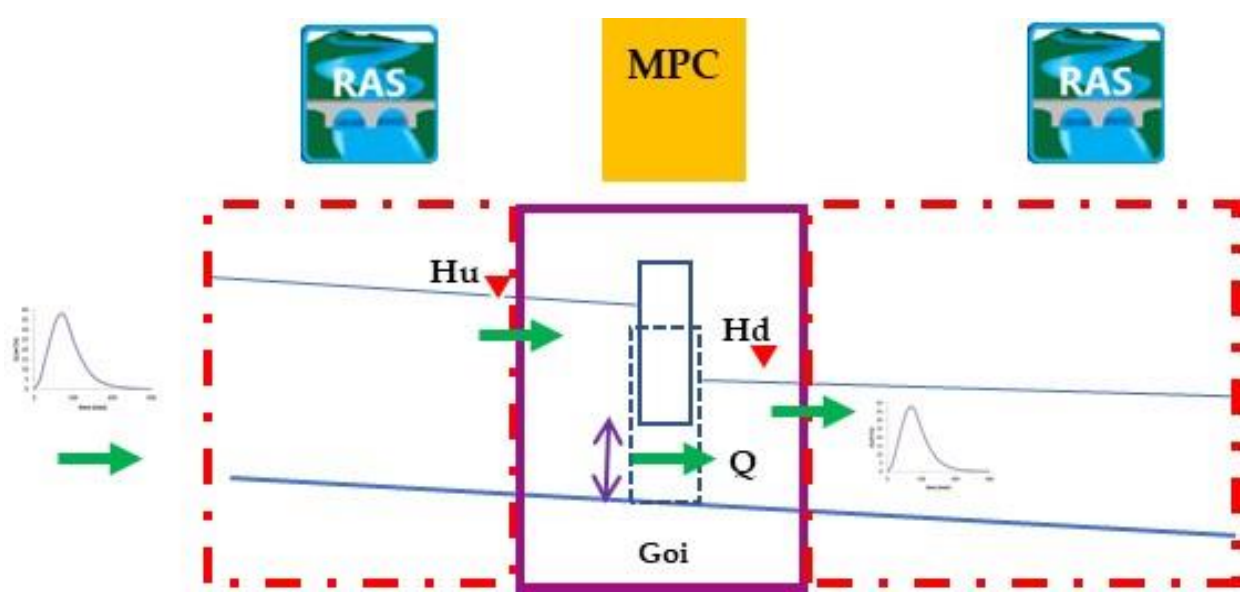

Fig. 10. Cascade Model link concept.

$$
\begin{gathered}
\mathrm{Q}=\mathrm{C} . \mathrm{Go} . \mathrm{L} \sqrt{2 \mathrm{~g}\left(\mathrm{H}_{\mathrm{U}}-\mathrm{H}_{\mathrm{d}}\right)} \\
\mathrm{Hu}=\mathrm{H}_{\mathrm{d}}+\frac{\left(\frac{\mathrm{Q}}{\text { C.G.L }}\right)^{2}}{2 \mathrm{~g}}
\end{gathered}
$$

where:

$L$ is the width of the structure $(m), H u$ and $H d$ are the water levels upstream and downstream,

$C$ is the discharge coefficients (0.6-0.7), and Go is the gate's opening.

From equation (9), a prediction model calculates the upstream water level at the regulator in each cascade to use with the MPC in the next step. Equation (5) can be converted to a prediction model in MATLAB Simulink.

\section{(2) Cost Function for Optimization}

The regulatory control for each regulator in the cascade expects an automatic adjustment of the controlled structures with reliability and durability. For instance, a gate is moved up and down to regulate the flow rate at the end of a reach close to the reference value (set-point). The control input $\mathrm{u}$, i.e., the acceleration command, is calculated by solving the constrained optimization problem below during each sampling period; the cost function of each controller is as shown in equation (6):

$$
\min _{U} J=\sum_{i=1}^{N}\left(T W L_{i}-C W L\right)^{2} W x_{i}+\sum_{i=1}^{N} \Delta u i^{2} W u_{i}
$$

where:

CWL (Control Water Level) is the controlled variable over the prediction horizon $p$, TWL (Target water level) is the target reference water level value, $u$ is manipulated input (gate opening) over prediction horizon $p$, and Wxi and Wui are the weighting matrices of appropriate dimensions. 


\section{(3) MPC Parameter}

MATLAB ${ }^{\circledR}$, Simulink ${ }^{\circledR}$, and Model Predictive Control Toolbox ${ }^{\mathrm{TM}}$ were used to simulate cascade networks. The optimization problem is solved by a QP solver, based on the KWIK algorithm, in the Model Predictive Control Toolbox. The "MPC Controller" block is used to model the controller and run the closed-loop simulation with the plant model in Simulink. C-code can be generated from the MPC block for the implementation to an embedded microprocessor. The simulation applied the cascade dimension from Table 1 and the simulation parameters from Table 2.

Table 2.

Simulation Parameters.

\begin{tabular}{ll}
\hline Parameter & Value \\
\hline Prediction horizon $(\mathrm{p})$ & 60 \\
Control horizon $(\mathrm{Np})$ & 2 \\
Simulation time $(\mathrm{T})$ & $60 \mathrm{~min}$. \\
Time step $(\mathrm{T})$ & $5 \mathrm{~min}$ \\
Weight.MV & 0 \\
Weight.OV & 1 \\
\hline
\end{tabular}

\subsubsection{HECRAS Configuration}

Cascade MPC examined flow profile in river with HECRAS model, calibrate model using the measured values of the M.164 station. The results are shown in Fig.11, with a confidence value of r2 of approximately 0.9928 .
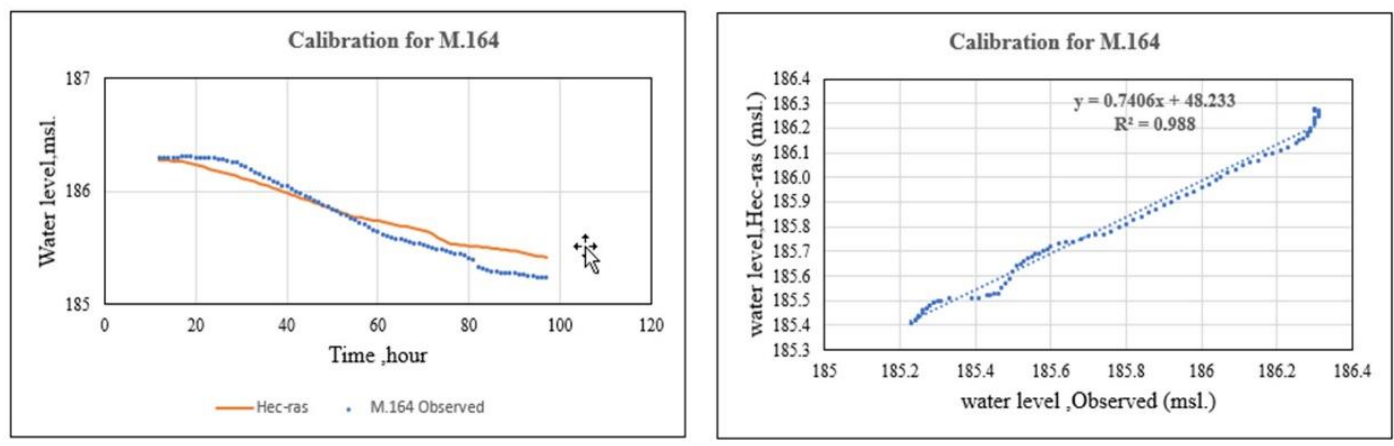

Fig. 11. Calibration for M.164 at Nakhorn Ratchasrima City.

\section{RESULTS AND DISCUSSIONS}

\subsection{Cascade Network Test Run}

According to the existing hydraulic structures in the Lamtakong River, the cascades were considerably divided into three groups, $\mathrm{A}, \mathrm{B}$, and $\mathrm{C}$, which are the upper stream reaches before reaching the junction of the Lamboriboon River, the Lamboriboon River, and the Lamtakong River, respectively, from the boundary of Group A to the lower stream where the Lanboriboon converges back with the main Lamtakong, as shown in Fig. 7. The cascade test run was conducted using the October 2013 flood event where the maximum flow through the city was $25 \mathrm{cms}$. Fig. 12 shows the examples of water levels along the $\mathrm{C}$ group cascade, which consist of CC3, CC4, CC5, CC6, and CC7, compared with the target water level of the reach. The proper gate opening of each regulator in the cascades from 19:00 October 23, 2013, to 13:00 October 24, 2013, is summarized in Table 3. 


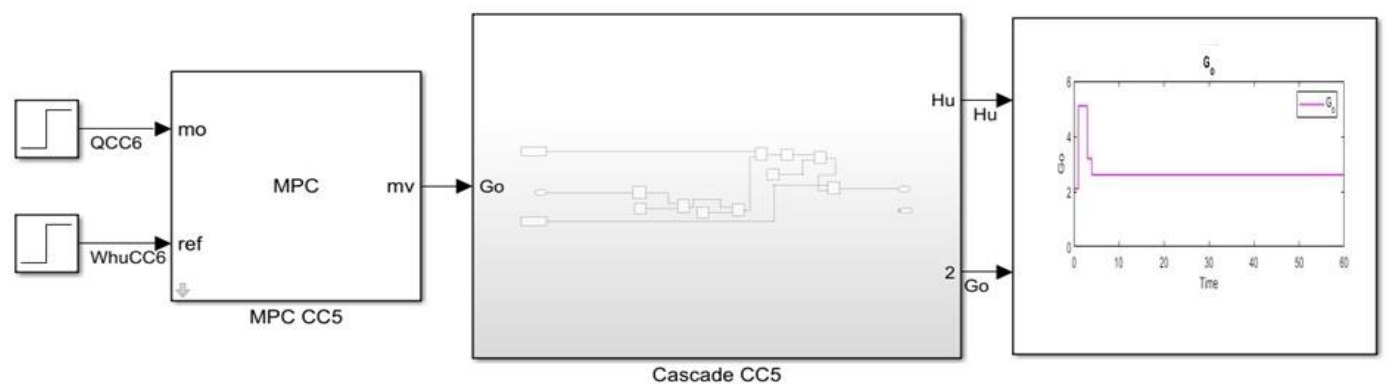

Fig. 12. Control diagram and recommend gate opening for CASCADE CC5.

Table 3.

Proper Lifting Height of each Gate in the Cascade, Recommended by MPC.

\begin{tabular}{llll}
\multirow{2}{*}{$\begin{array}{l}\text { Cascade } \\
\text { Gate Lifting Height }\end{array}$} & \multicolumn{2}{c}{ Time } \\
\cline { 3 - 4 } & & \multicolumn{1}{c}{ From } & \multicolumn{1}{c}{ To } \\
\hline CC3 & 2.5 to 1.5 & $10 / 23 / 201319.00$ & $10 / 23 / 201320.00$ \\
CC4 & 3.0 to 1.8 & $10 / 23 / 201321.30$ & $10 / 23 / 201322.30$ \\
CC5 & 4.5 to 2.2 & $10 / 24 / 201300.30$ & $10 / 24 / 201301.30$ \\
CC6 & 4.0 to 2.0 & $10 / 24 / 20134.00$ & $10 / 24 / 201305.00$ \\
CC7 & 4.0 to 2.0 & $10 / 24 / 201312.00$ & $10 / 24 / 201313.00$ \\
\hline
\end{tabular}

\subsection{Flood Management Comparison}

This study has applied the cascade MPC control to manage a flood by utilizing a stream's maximum capacity, using existing regulators in rivers. First, the target water level of each reach is designated under local constraints; then the best-case water level condition is calculated using looping procedures in spatial and global scales, in order of steps. Finally, the suggested water level for the flood period operation is further implemented and controlled by the gate opening set.

Fig 13 illustrates water levels at Nakhon Ratchasima city, both the actual situation and the circumstance under the pro-posed gate management strategy. The $0.5 \mathrm{~m}$ water level which was lower than the riverbank indicates the advantage of applying the cascade MPC during the peak flow period.

Fig. 14 illustrates the comparison of the GIS flood map in year 2013 and the flood map that was controlled by Cascade MPC. The figure shows that Cascade MPC can reduce the areas of a flood map in the city from 15,939 Rai to 5,944 Rai (more than 60\%.)

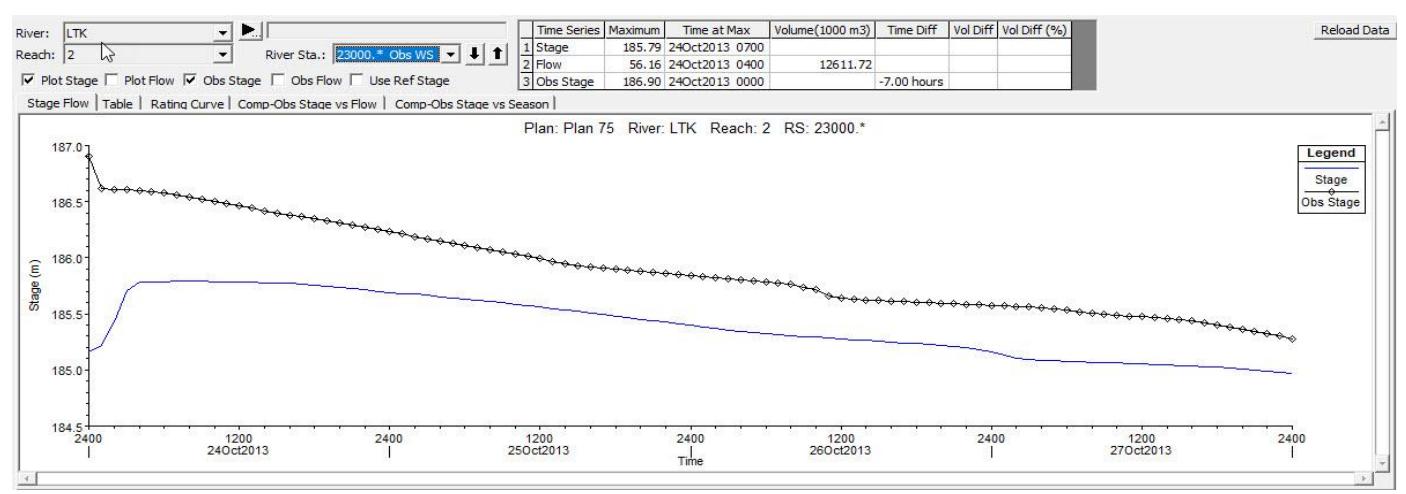

Fig. 13. Comparison of water level at Nakhon Ratchasima City between actual conditions and the result from Cascade MPC. 


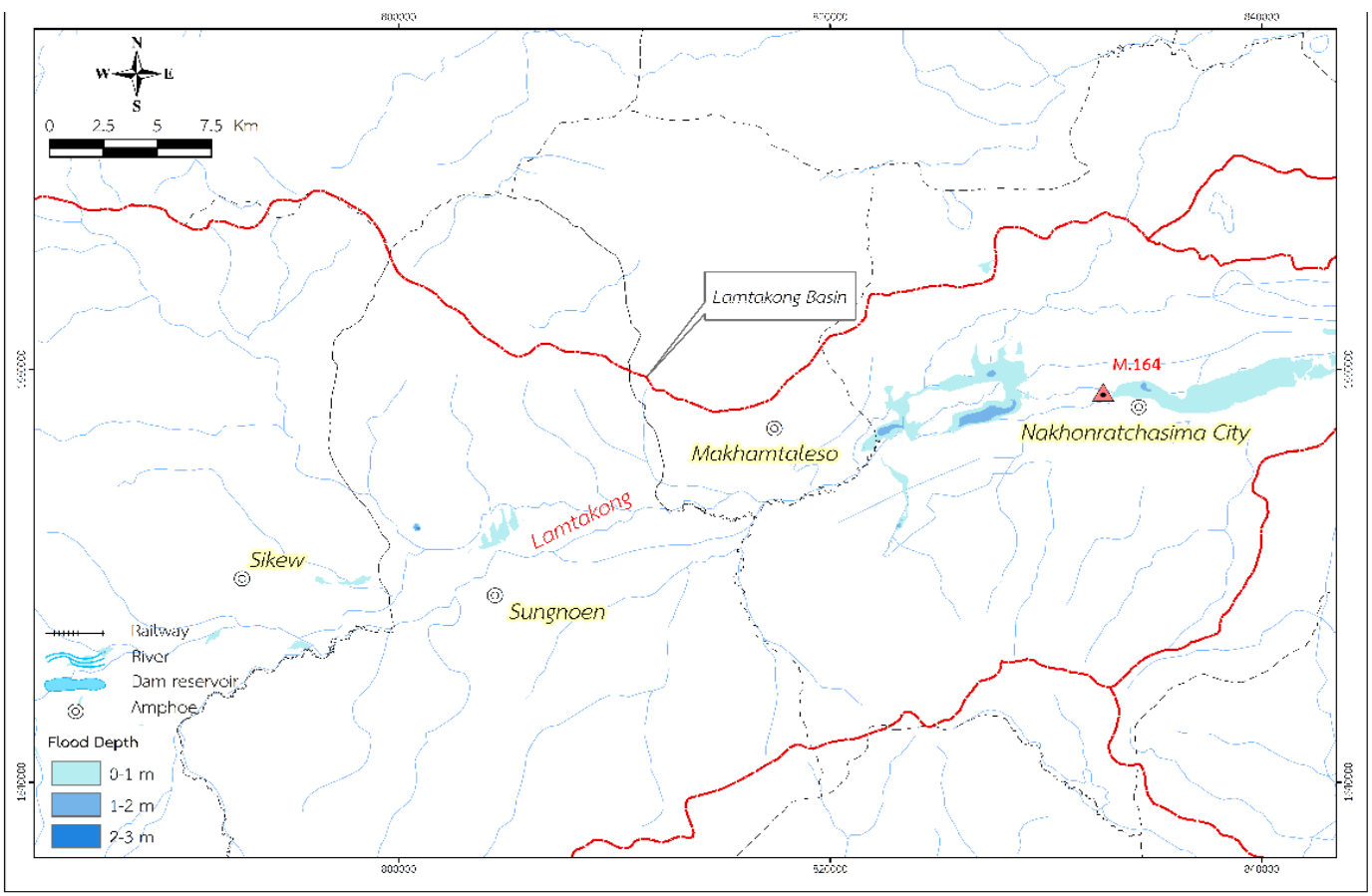

a) Existing condition in year 2013 .

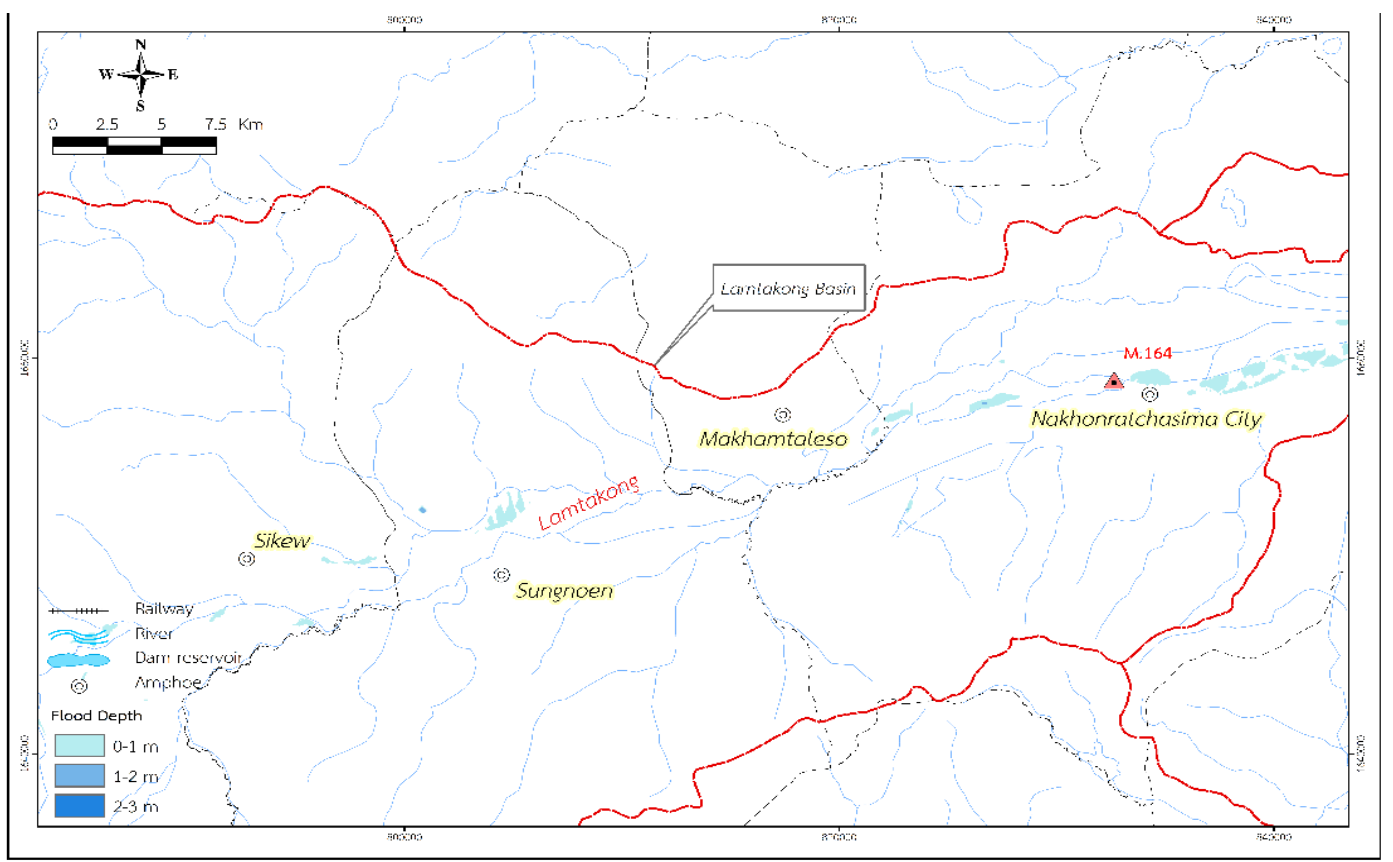

b) Flood management by Cascade MPC.

Fig. 14. Comparison of existing flood map in year 2013 and flood map by Cascade MPC. 


\section{CONCLUSIONS}

The Lamtakong River in Nakorn Ratchasima Province is a large-scale river with several branches that flows through communities to eventually converge with the Mun River downstream. Generally, the water is conserved for irrigation purposes; thus, the local RID staff manually regulates the hydraulic structures based on their experience with water levels. However, during a flood period, the regulator's function is shifted to prevent and mitigate disaster along flood-affected communities and economic areas. Although any flood situation is reported from the upstream reaches to the command center from time to time, operating the movable gates in the river is a local decision that depends on operators' experiences. Regardless of the effects on the overall system performance or a future situation, it could cause an unpredictable impact on other areas.

This study proposes the concept of combining real-time flood management with the cascade Model Predictive Control, taking the most advantage of the pre-existing thirteen regulating structures and controlling the flow cascade to cascade. The 2013 flood event, where the maximum flow was 90 $\mathrm{cum} / \mathrm{s}$, is applied to the Lamtakong River and the Lamboriboon branch to verify the proposed concept. First, the flood situation is of primary concern, in which the condition of local flood management limits with its reach embankment elevation. Once the flow upstream enters the system, all gate setting heights are precalculated, and the water level at the monitoring station, M.164, is rechecked. The realtime gate opening data is updated. The gate opening height of all regulators downstream are recalculated and compared with the target water level. The global image of the basin will then be relooped. The objective functions and constraints are changed. The model then goes through the optimization process using the trial gate opening step, Go, until it meets the minimum error point. Under the global flood prevention conditions, the optimized gate settings are finally proposed to the local controllers within a few minutes of computer analyses.

The comparison of the flood map between the historical flood in year 2013 and flood management with the cascade Model Predictive Control shows that the cascade MPC model can alleviate flooding in the city by almost $100 \%$. Notably, there are still flood areas on both sides of Lamtakong in the paddy field areas, in an acceptable situation. In addition, comparing with the actual situation in 2013, according to the gates operating under the MPC recommendation, the water level at Nakhon Ratchasima City was $0.5 \mathrm{~m}$ lower than the riverbank and can alleviate the GIS flood area by more than 60 percent. This indicates the advantage of applying the proposed concept of combining realtime flood management with the cascade MPC during the peak flow period.

\section{R E F E R E N C ES}

Barjas Blanco, Toni, Patrick Willems, Bart De Moor, and Jean Berlamont. 2008. 41 IFAC Proceedings Volumes Flooding Prevention of the Demer River Using Model Predictive Control. IFAC. http://dx.doi.org/10.3182/20080706-5-KR-1001.00613.

Breckpot, Maarten et al. 2013. "Flood Control of the Demer by Using Model Predictive Control." Control Engineering Practice 21(12): 1776-87. http://dx.doi.org/10.1016/j.conengprac.2013.08.008.

Department(RID)Thailand., Royal Irrigation. 2020. "Hydrology Data." http://hydro-4.rid.go.th/.

Evans, R. et al. 2011. "Real-Time Optimal Control of River Basin Networks." IFAC Proceedings Volumes (IFAC-PapersOnline) 44(1 PART 1): 11459-64.

Falk, Anne Katrine Vinther, Craig MacKay, Henrik Madsen, and Peter Nygaard Godiksen. 2016. "Model Predictive Control of a Large-Scale River Network." Procedia Engineering 154: 80 87. http://dx.doi.org/10.1016/j.proeng.2016.07.422. 
Leon, Arturo S., Elizabeth A. Kanashiro, Rachelle Valverde, and Venkataramana Sridhar. 2014. "Dynamic Framework for Intelligent Control of River Flooding: Case Study." Journal of Water Resources Planning and Management 140(2): 258-68.

López Rodríguez, F., K. Horváth, J. García Martín, and J. M. Maestre. 2017. "Mobile Model Predictive Control for the Évora Irrigation Test Canal." IFAC-PapersOnLine 50(1): 6570-75. Modelling, Environmental, and Arturo Segundo Leon. 2018. "Controlling HEC-RAS Using MATLAB Controlling HEC-RAS Using MATLAB.” (October 2016): 1-13.

Nguyen, Le Duy Lai, Ionela Prodan, Laurent Lefevre, and Denis Genon-Catalot. 2017. "Distributed Model Predictive Control of Irrigation Systems Using Cooperative Controllers." IFACPapersOnLine 50(1): 6564-69. https://doi.org/10.1016/j.ifacol.2017.08.612.

Song, Mengjie, Ning Mao, Haoran Zhang, and Cheng Fan. 2020. Advanced Analytic and Control Techniques for Thermal Systems with Heat Exchangers Model Predictive Control Applied toward the Building Indoor Climate. Elsevier Inc. http://dx.doi.org/10.1016/B978-0-12819422-5.00021-9.

Tian, Xin et al. 2017. "Efficient Multi-Scenario Model Predictive Control for Water Resources Management with Ensemble Streamflow Forecasts.” Advances in Water Resources 109: 5868.

USACE - Environmental Laboratory. 1987. "Wetlands Delineation Manual -Final Report.” 1(January): 143. http://www.lrh.usace.army.mil/Portals/38/docs/USACE 87 Wetland Delineation Manual.pdf.

Vermuyten, Evert. 2018. "Real-Time Flood Control by Means of Model Predictive Control and a Reduced Genetic Algorithm.” (July).

Wahlin, Brian, and Darell Zimbelman. 2018. "Canal Automation for Irrigation Systems: American Society of Civil Engineers Manual of Practice Number 131." Irrigation and Drainage 67(1): 22-28.

Wang, Y. et al. 2017. “Optimal Management of Barcelona Water Distribution Network Using NonLinear Model Predictive Control." IFAC-PapersOnLine 50(1): 5380-85. https://doi.org/10.1016/j.ifacol.2017.08.1070. 